Original Article

\title{
Effects of whole-body vibration therapy on perception thresholds of type 2 diabetic patients with peripheral neuropathy: a randomized controlled trial
}

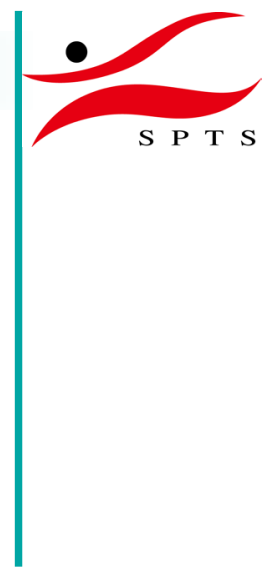

\author{
Kyeonguin Lee, PT, PhD ${ }^{1)}$ \\ 1) Department of Physical Therapy, Kyungdong University: 815 Gyeonhwon-ro, Huyong-ri, \\ Munmak-eup, Wonju-si, Gangwon-do 26495, Republic of Korea
}

\begin{abstract}
Purpose] The aim of this study was to investigate the effect of whole-body vibration training on perception thresholds in type 2 diabetic patients with peripheral neuropathy. [Subjects and Methods] Fifty-nine patients with diabetic neuropathy participated in the study. They were randomly divided into the experimental group $(n=29)$ and the control group $(n=30)$. The experimental group performed whole-body vibration training, whereas the control group performed only lower body training in the same posture without using whole-body vibrator for 6 weeks. Perception threshold variables were measured to examine the effect of training. [Results] Warm and cold pain thresholds did not show significant changes in both groups before and after training. Vibration perception threshold showed significant improvement in the experimental group. [Conclusion] Our findings suggest that whole-body vibration training can improve vibration perception threshold of type 2 diabetic patients with peripheral neuropathy.

Key words: Diabetes, Whole-body vibration, Perception threshold
\end{abstract}

(This article was submitted May 23, 2017, and was accepted Jun. 20, 2017)

\section{INTRODUCTION}

Type 2 diabetes is a metabolic disorder closely related to aging ${ }^{1)}$. The International Diabetes Federation estimates that there will be approximately 642 million diabetics by $2040^{2}$. More than $90 \%$ of diabetic patients have type 2 diabetes, and 94 million of the elderly are aged between 65 and 79 years ${ }^{2}$.

Diabetes itself is a problem, but more problems are caused by secondary diseases such as cardiovascular and metabolic diseases ${ }^{3)}$. Diabetic complications mainly include circulatory disturbances resulting from ischemia and hypoxia in peripheral tissues due to inappropriate blood glucose $\operatorname{control}^{4)}$. Typical complications include vascular complications, such as diabetic retinopathy and nephropathy, and neuropathy and diabetic foot ${ }^{3,4)}$.

Diabetic neuropathy is a common complication that occurs in more than half of diabetic patients, causing disturbance of balance due to central and peripheral nervous system transmission disturbances ${ }^{5}$. Loss of sensory perception delays response time to the stimulus and reduces muscle-nervous system response ${ }^{6}$. The lack of inherent receptive sensory feedback from the lower limb leads to posture instability ${ }^{7}$. Diabetic neuropathy patients are at increased risk of falls ${ }^{5,8)}$. Therefore, treatment and management of neuropathic diabetes mellitus aims to improve peripheral nerve senses as well as blood glucose $\operatorname{control}^{9)}$.

Whole-body vibration (WBV) has been used in patients with neurological or musculoskeletal disorders as a new and effective intervention method to improve physical function ${ }^{10,11)}$. WBV recently has been applied to improve the strength and balance of diabetic patients ${ }^{12,13)}$, but it is yet to be applied as a therapeutic method for improving sensation. 
The effect of WBV is manifested by muscle contraction, facilitation of sensory inputs, and stimulation of proprioceptive receptors. A few studies have tried to improve perception threshold with $\mathrm{WBV}^{14-16)}$. One study found that the vibro-tactile threshold decreased after 48 hours of short-term WBV application in healthy adults, but the acute response of a single WBV increased ${ }^{15)}$. Therefore, the need for longer interventions is being discussed to improve tactile threshold ${ }^{15}$. Another study reported that WBV in healthy adults reduced plantar foot sensitivity and improved balance control ${ }^{16)}$.

Perception threshold has been previously used to screen for neuropathy, and it is important to identify the effect of WBV on perception threshold in patients who are at risk of neuropathy, such as patients with diabetes.

The aim of this study was to verify the effect of 6-week WBV training on perception thresholds of neuropathic diabetic elderly.

\section{SUBJECTS AND METHODS}

We recruited 78 type 2 diabetic elderly people who participated in the exercise program at the K-Welfare Center in Republic of Korea. Inclusion criteria were age of 65 years and older, one or more falls within the past 12 months, and diabetic peripheral neuropathy diagnosed by a physician. Exclusion criteria were presence of musculoskeletal abnormality, inability to stand independently, neurological impairment, and a Mini-Mental State Examination score of less than 24 .

We explained each subject all the experimental procedures and got their written consent. All experiments were conducted with the confirmation of institutional review board of Sahmyook University. This study was a single-blinded randomized controlled trial. Sixty subjects who met the selection criteria were randomly divided into two groups, the experimental group ( $\mathrm{n}=30)$ and the control group $(\mathrm{n}=30)$, using Random Allocation Software (version 2.0) (Fig. 1).

The experimental group performed WBV training using whole body vibrator for 11 minutes per session 3 times a week for 6 weeks, whereas the control group performed lower body training in the same posture without using the whole-body vibrator for 11 minutes per session 3 times a week for 6 weeks. WBV training was performed under the supervision of a physical therapist by using a vibration platform (Galileo 2000, Novotec Medical GmBH, Germany). The subject stood on the platform with his/her feet barefoot shoulder width and stared at the front. The subject bent the knee a little $\left(30^{\circ}\right)$, so that vibration did not reach up to the head. To prevent falls, the subject held the railing. Anyone who felt fatigue or dizziness during training had a rest. The training was performed at a frequency of $12 \mathrm{~Hz}$ and amplitude of $1-3 \mathrm{~mm}$. The training comprised of $3 \times 3-\mathrm{min}$ bouts of WBV with 1-min intervals between bouts. The control group was trained at the same time, position, and frequency as the experimental group but without WBV.

Thermal perception thresholds, including warm and cold thresholds, were assessed by a thermal sensory analyzer (TSA-II, MEDOC, Ramat Yishai, Israel). Thermal thresholds were derived using a feedback controlled Peltier stimulator with a $9 \mathrm{~cm}^{2}$ contact area. A modified Marstock protocol ('method of limits' protocol in the TSA-II software) was used to determine warm and cold stimuli detection thresholds. The protocol started with the thermal probe comfortably strapped to the test site for $1 \mathrm{~min}$ at an adapting temperature of $32^{\circ} \mathrm{C}$. Thereafter, the temperature was increased (or decreased in separate blocks of trials) at a rate of $1{ }^{\circ} \mathrm{C} / \mathrm{s}$ until the subject pushed the response button to indicate that he/she felt the warm and the cold pain stimuli. At that point, the probe temperature returned to the adapting temperature for an inter-stimulus interval of $6-10 \mathrm{~s}$ before the next stimulus. The threshold was taken as the median temperature at the time of the button press of 4 trials.

Vibratory thresholds were additionally measured using a vibratory sensory analyzer (VSA-3000, Medoc, Minneapolis, MN, USA). This computerized device vibrated at a constant frequency $(100 \mathrm{~Hz})$, with amplitude increasing from 0 to $25 \mu \mathrm{m}$. The vibrator head was placed over the skin at a constant force pressure and the patient was asked to press a signal-button immediately at the first perception of vibration. The vibratory threshold, expressed in micrometers, was defined as the mean of 5 consecutive trials. Vibration perception threshold (VPT) was quantified using the "method of limits," a protocol in which repeated increasing vibratory stimulation is applied to the plantar aspect of the dominant great toe. Subjects pushed a button on a hand-held indicator as soon as they detected vibration. 
Table 1. General characteristics of the subjects

\begin{tabular}{lccc}
\hline & $\begin{array}{c}\text { All } \\
(\mathrm{N}=59)\end{array}$ & $\begin{array}{c}\text { Experimental group } \\
(\mathrm{n}=29)\end{array}$ & $\begin{array}{c}\text { Control group } \\
(\mathrm{n}=30)\end{array}$ \\
\hline Age (years) & $71.8 \pm 4.0$ & $71.3 \pm 3.7$ & $72.1 \pm 4.3$ \\
Height $(\mathrm{cm})$ & $163.4 \pm 8.2$ & $164.8 \pm 6.8$ & $161.9 \pm 9.3$ \\
Weight $(\mathrm{kg})$ & $61.8 \pm 8.3$ & $62.7 \pm 7.4$ & $60.9 \pm 9.1$ \\
BMI $\left(\mathrm{kg} / \mathrm{m}^{2}\right)$ & $6.8 \pm 2.1$ & $23.1 \pm 2.4$ & $23.1 \pm 1.8$ \\
Gender (male/female) & $37 / 22$ & $19 / 10$ & $18 / 12$ \\
History of falls(Yes/No) & $39 / 20$ & $20 / 9$ & $19 / 11$ \\
Medication (Yes/No) & $41 / 18$ & $21 / 8$ & $20 / 10$ \\
Exercise (regular/non-regular) & $17 / 25$ & $1 / 11$ & $16 / 14$ \\
Perceived general health (Fair/Poor) & $46 / 59$ & $16 / 34$ & $30 / 25$ \\
Duration of diabetes (years) & $15.9 \pm 6.8$ & $15.4 \pm 7.1$ & $16.3 \pm 6.7$ \\
Hemoglobin Alc (\%) & $8.4 \pm 1.1$ & $8.5 \pm 1.1$ & $8.2 \pm 1.1$ \\
MMSE (points) & $25.8 \pm 1.1$ & $25.8 \pm 1.2$ & $25.7 \pm 0.9$ \\
\hline
\end{tabular}

BMI: body mass index; MMSE: mini mental state examination

Values are expressed as mean \pm standard deviation.

Table 2. Comparison of perception thresholds between experimental and control group $(\mathrm{N}=59)$

\begin{tabular}{llcc}
\hline & & $\begin{array}{c}\text { Experimental group } \\
(\mathrm{n}=29)\end{array}$ & $\begin{array}{c}\text { Control group } \\
(\mathrm{n}=30)\end{array}$ \\
\hline $\mathrm{CPT}\left({ }^{\circ} \mathrm{C}\right)$ & Pre & $10.7 \pm 5.7$ & $11.5 \pm 5.7$ \\
& Post & $10.9 \pm 6.8$ & $10.6 \pm 3.1$ \\
& Pre-Post & $0.3 \pm 6.6$ & $-0.9 \pm 6.1$ \\
\hline HPT $\left({ }^{\circ} \mathrm{C}\right)$ & Pre & $50.7 \pm 6.7$ & $51.6 \pm 8.5$ \\
& Post & $48.2 \pm 9.6$ & $48.5 \pm 9.5$ \\
& Pre-Post & $-2.5 \pm 10.8$ & $-3.1 \pm 13.6$ \\
\hline VPT $(\mathrm{mm})$ & Pre & $45.4 \pm 16.8$ & $41.1 \pm 19.2$ \\
& Post & $35.7 \pm 17.6$ & $40.1 \pm 19.2$ \\
& Pre-Post & $-9.7 \pm 17.3^{* \dagger}$ & $-1.0 \pm 7.6$ \\
\hline CPT: cold & pain threshold; WPT: warm pain threshold; & prostion \\
VPT: vibration perception threshold & \\
Values are expressed as mean \pm standard deviation. \\
*means significant difference within group. \\
†means significant difference between groups.
\end{tabular}

These examinations were performed double-blinded. First, the switch of the stimulator was manipulated by a physician (not the person performing the sensory testing session). Secondly, the patients did not experience any sensory or motor sensation at stimulator switching, and therefore could not detect it. This test, as a measure of physical mobility, has good intrarater and interrater reliability $(\mathrm{r}=0.90 \text { and } 0.84 \text {, respectively })^{17)}$.

All statistical analyzes were performed using 19 version of SPSS statistical package. The Shapiro-Wilks test was used to check for normality, and all values were normally distributed. Independent $t$-test and $\chi^{2}$ test were performed for comparisons of general characteristics of participants between the two groups, and paired t-test was conducted to compare general characteristics of participants before and post WBV training. Statistical significance was defined as $\mathrm{p}$ value $<0.05$.

\section{RESULTS}

The total number of subjects in this study was 59 (experimental group=29, control group=30). One participant dropped out of the experimental group due to personal reasons. The attendance rate of training sessions was over $90 \%$. Table 1 shows the general characteristics of subjects in the study. There were no significant differences between the two groups.

Thermal perception threshold was evaluated as the warm pain threshold (WPT), cold pain threshold (CPT), and VPT. WPT and CPT did not show significant changes in both groups before and after training. VPT showed significant improvement in the experimental group $(\mathrm{p}<0.05)$ but not in the control group. There was a significant difference between the groups in the pre-post change $(\mathrm{p}<0.05)$ (Table 2$)$.

\section{DISCUSSION}

The purpose of this study was to investigate the effect of whole-body vibration on WPT, CPT, and VPT to improve sensory 
threshold in patients with diabetic neuropathy. In the present study, the WPT and CPT did not change after intervention, and VPT significantly improved in the whole-body vibration group.

In this study, the mean age of patients was 70 years or older. The duration of diabetes mellitus was over 15 years and mean $\mathrm{HbA} 1 \mathrm{c}$ was more than $8.4 \%$, suggesting that diabetic complications such as neuropathy are progressing. Progression of neuropathy depends on the duration and severity of diabetes mellitus. The longer the duration of the disease, the more severe the neuropathy is ${ }^{18)}$. Compared with subjects in J Pfützner, et al. ${ }^{19)}$ and O Kalter-Leibovici, et al. ${ }^{20)}$ papers, CPT and HPT of the subjects in this study had similar values of 10.7 and 50.7, respectively, but VPT was 45.4, indicating that the degree of diabetic complication, neuropathy, was more severe.

In this study, WPT and CPT showed no significant changes after intervention. It is thought that vibration stimulation in WBV training did not affect temperature receptors.

When a diabetic patient is trained, the body decomposes glucose to supply energy, which causes blood glucose to drop. In addition, as blood circulation in the body increases, the amount of glucose and insulin delivered to the muscles increases, resulting in increased glucose levels in the peripheral tissues. As a result, insulin sensitivity is increased, and microcirculation, perfusion rate, and peripheral sensory function are improved $\left.{ }^{4}, 21\right)$. This physiological mechanism seems to be effective in improving peripheral sensory function of WBV of this study. In this study, VPT decreased by $21 \%$ in the experimental group after WBV.

Tactile receptors require time to adapt to vibration ${ }^{22}$. MA Hernandez-Mocholi, et al. ${ }^{15}$ ) found that tactile threshold increased after a single WBV session but the 48 hours of short-term WBV, requiring longer intervention. A 6-week intervention period in this study was thought to play a key role in increasing sensitivity of native receptors and lowering threshold of tactile receptors by providing the body with the opportunity to adapt to repeated vibration input.

Tactile receptors of the sole and proprioception are important sensory mechanisms for posture control that provide feedback and feedforward information ${ }^{23)}$. Lack of this sense limits movement correction, and inaccurate movement leads to a lack of normal sensation and vice versa $\left.{ }^{23}, 24\right)$. These senses play an important role in balance and walking ${ }^{24)}$. Future research will need to further focus on balance and gait improvement through sensory enhancement of patients with diabetic neuropathy through WBV training.

The limitation of this study is that it does not clarify the mechanism of the unfavorable effect of WBV training on the temperature sensation. In addition, there are no studies on perception thresholds affected by intervention, and the results of this study could not be compared.

This study confirmed the improvement in VPT by applying WBV to elderly patients with diabetic neuropathy, and it is thought to be a cornerstone for patients with sensory impairment.

\section{REFERENCES}

1) Camargo MR, Barela JA, Nozabieli AJ, et al.: Balance and ankle muscle strength predict spatiotemporal gait parameters in individuals with diabetic peripheral neuropathy. Diabetes Metab Syndr, 2015, 9: 79-84. [Medline] [CrossRef]

2) Federation ID: IDF Diabetes Atlas Seventh edition. http://www.idf.org/diabetesatlas

3) Forbes JM, Cooper ME: Mechanisms of diabetic complications. Physiol Rev, 2013, 93: 137-188. [Medline] [CrossRef]

4) Matsumoto Y, Ohno H, Noguchi I, et al.: Disturbance of microcirculation due to unhealthy lifestyle: cause of type 2 diabetes. Med Hypotheses, 2006 , 66: 550-553. [Medline] [CrossRef]

5) Agrawal Y, Carey JP, Della Santina CC, et al.: Diabetes, vestibular dysfunction, and falls: analyses from the National Health and Nutrition Examination Survey. Otol Neurotol, 2010, 31: 1445-1450. [Medline]

6) Richardson JK: The clinical identification of peripheral neuropathy among older persons. Arch Phys Med Rehabil, 2002, 83: 1553-1558. [Medline] [CrossRef]

7) Mueller MJ, Minor SD, Sahrmann SA, et al.: Differences in the gait characteristics of patients with diabetes and peripheral neuropathy compared with agematched controls. Phys Ther, 1994, 74: 299-308, discussion 309-313. [Medline] [CrossRef]

8) Mustapa A, Justine M, Mohd Mustafah N, et al.: Postural control and gait performance in the diabetic peripheral neuropathy: a systematic review. BioMed Res Int, 2016, 2016: 9305025. [Medline] [CrossRef]

9) Najafi B, Crews RT, Wrobel JS: A novel plantar stimulation technology for improving protective sensation and postural control in patients with diabetic peripheral neuropathy: a double-blinded, randomized study. Gerontology, 2013, 59: 473-480. [Medline] [CrossRef]

10) Orr R: The effect of whole body vibration exposure on balance and functional mobility in older adults: a systematic review and meta-analysis. Maturitas, 2015 , 80: 342-358. [Medline] [CrossRef]

11) Yang $\mathrm{X}$, Wang P, Liu C, et al.: The effect of whole body vibration on balance, gait performance and mobility in people with stroke: a systematic review and meta-analysis. Clin Rehabil, 2015, 29: 627-638. [Medline] [CrossRef]

12) Lee K, Lee S, Song C: Whole-body vibration training improves balance, muscle strength and glycosylated hemoglobin in elderly patients with diabetic neuropathy. Tohoku J Exp Med, 2013, 231: 305-314. [Medline] [CrossRef]

13) Robinson CC, Barreto RP, Sbruzzi G, et al.: The effects of whole body vibration in patients with type 2 diabetes: a systematic review and meta-analysis of randomized controlled trials. Braz J Phys Ther, 2016, 20: 4-14. [Medline] [CrossRef]

14) Fanchiang HD, Geil M, Wu J, et al.: The effects of vibration on the gait pattern and vibration perception threshold of children with idiopathic toe walking. J Child Neurol, 2015, 30: 1010-1016. [Medline] [CrossRef]

15) Hernandez-Mocholi MA, Dominguez-Muñoz FJ, Corzo H, et al.: Whole body vibration training improves vibration perception threshold in healthy young 
adults: a randomized clinical trial pilot study. J Musculoskelet Neuronal Interact, 2016, 16: 12-17. [Medline]

16) Schlee G, Reckmann D, Milani TL: Whole body vibration training reduces plantar foot sensitivity but improves balance control of healthy subjects. Neurosci Lett, 2012, 506: 70-73. [Medline] [CrossRef]

17) Felix ER, Widerström-Noga EG: Reliability and validity of quantitative sensory testing in persons with spinal cord injury and neuropathic pain. J Rehabil Res Dev, 2009, 46: 69-83. [Medline] [CrossRef]

18) Tesfaye S, Chaturvedi N, Eaton SE, et al. EURODIAB Prospective Complications Study Group: Vascular risk factors and diabetic neuropathy. N Engl J Med, 2005, 352: 341-350. [Medline] [CrossRef]

19) Pfützner J, Hellhammer J, Musholt P, et al.: Evaluation of dexterity in insulin-treated patients with type 1 and type 2 diabetes mellitus. J Diabetes Sci Technol, 2011, 5: 158-165. [Medline] [CrossRef]

20) Kalter-Leibovici O, Yosipovitch G, Gabbay U, et al.: Factor analysis of thermal and vibration thresholds in young patients with Type 1 diabetes mellitus. Diabet Med, 2001, 18: 213-217. [Medline] [CrossRef]

21) Devlin JT, Hirshman M, Horton ED, et al.: Enhanced peripheral and splanchnic insulin sensitivity in NIDDM men after single bout of exercise. Diabetes, 1987, 36: 434-439. [Medline] [CrossRef]

22) Lundström RJ: Responses of mechanoreceptive afferent units in the glabrous skin of the human hand to vibration. Scand J Work Environ Health, 1986, 12: 413-416. [Medline] [CrossRef]

23) Armstrong WJ, Nestle HN, Grinnell DC, et al.: The acute effect of whole-body vibration on the hoffmann reflex. J Strength Cond Res, 2008, 22: 471-476. [Medline] [CrossRef]

24) Menz HB, Morris ME, Lord SR: Foot and ankle characteristics associated with impaired balance and functional ability in older people. J Gerontol A Biol Sci Med Sci, 2005, 60: 1546-1552. [Medline] [CrossRef] 